\title{
Perceptions by Hispanics of channels and sources of health messages regarding cigarette smoking
}

\author{
Gerardo Marín
}

\begin{abstract}
Objective-To identify the perceptions that two communities of urban Hispanics have of various sources and channels of information regarding cigarette smoking and to compare them with those of nonHispanic whites.

Design-Random samples of subjects of both ethnic groups and of both genders were surveyed by telephone to determine the perceived credibility and motivating power of 13 different channels of information and of 14 different sources of cigarette smoking information.

Subjects - 544 Hispanics and 542 nonHispanic whites from San Francisco, California and Houston, Texas, 18-65 years in age, of both genders.

Results - Differences in the proportion of respondents assigning various perceived qualities to sources and channels of information regarding cigarette smoking were found to exist across ethnic groups (Hispanics and non-Hispanic whites); the respondents' gender (particularly among Hispanics); and the acculturation level of the Hispanic respondents. Nevertheless, there was a cluster of channels (printed media and television news) and of sources (physicians, people with cancer, friends, and peers) that were positively evaluated by large proportions of the respondents in both ethnic groups.

Conclusions - Hispanics differ from nonHispanic whites in their evaluation of various possible sources and channels of information about tobacco control. Culturally appropriate interventions for Hispanics need to be designed so as to use those channels and sources of information that are more positively perceived by Hispanics.
\end{abstract}

(Tobacco Control 1996; 5: 30-36)

Keywords: Hispanics, credibility, sources, channels Psychology, University of San Francisco, 2130 Fulton Street, San Francisco, California 94117-1080, USA

Gerardo Marín
Department of

\section{Introduction}

The literature on social marketing, mass communication, and attitude change $e^{1-5}$ has frequently proposed that there is a need to use channels and sources of information that are appropriate for the group being targeted. Recent articles on the development of cult- urally appropriate interventions $s^{6,7}$ also have supported the need to identify effective ethnicos group-specific channels and sources of in-ते formation to reach the target audience. This ${ }^{2}$ article summarises the perceptions of a random $\vec{\omega}$ sample of Hispanics regarding a variety of possible sources and channels of information that could be used for the presentation of $\overrightarrow{3}$ health promotion messages dealing with cigarette smoking.

Although some information is currently $\vec{\circ}$ available on the evaluation of possible channels\% and sources of health promotion among nonHispanic whites, ${ }^{4}$ there is a significant lack of research addressing these issues among members of ethnic groups and particularly among. Hispanics. This limitation in the research base $\frac{0}{\alpha}$ makes it difficult for programme developers to $\stackrel{\vec{P}}{\overrightarrow{2}}$ identify optimal sources and channels of in-ô formation for health-promoting interventions. The need for a proper understanding of the perceptions of sources and channels is particularly critical in the area of tobacco edu- $\frac{0}{v}$ cation, as tobacco control interventions often make use of a variety of sources (such as physicians, entertainers, public figures, peers) $\stackrel{\circ}{7}$ and channels (for example, printed media, electronic media). In addition, research in the field of attitude and behaviour change ${ }^{3}$ has 3 . shown that, in many cases, the channel used in $ᄋ$ presenting information is more important than $₹$ the actual message in producing attitudinal, $\frac{}{5}$ behavioural, or informational changes, and $>$ that the perceived credibility of sources and을. channels is especially important in communi- N cation campaigns that demand low levels of involvement on the part of the receiver such as community-wide interventions and those that ${ }^{\mathrm{\omega}}$ use the mass media. ${ }^{8-10}$

The choice of channels of information is perceived by researchers ${ }^{11,12}$ as following speci- $\stackrel{\Phi}{+}$ fic personal needs of the recipients and their evaluation of the channel's characteris-

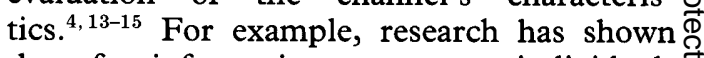
that, for information on cancer, individuals $\stackrel{\vec{Q}}{\mathbb{Q}}$ prefer to contact physicians and that cancer information provided by physicians is perceived as more accurate and credible than when presented by other sources. ${ }^{4,15}$

Although members of major ethnic groups in the United States account for approximately $28 \%$ of the total population, little is known about their reactions to the sources and channels currently used in the dissemination of

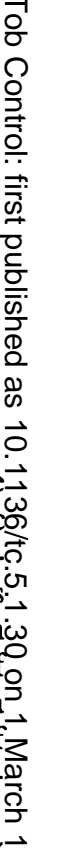


targeted tobacco control information. Research has shown group-specific preferences for certain channels depending on variables such as ethnic group, media availability, acculturation level of the recipient, gender, and educational level. ${ }^{16-18}$ Initial research with ethnic populations also has shown the existence of ethnicspecific preferences for various sources of health information. ${ }^{18,19}$ More importantly, research has begun to show ethnic group-specific differences in the ways in which various sources and channels of information are judged in terms of their credibility. For example, a study with African Americans ${ }^{20}$ found that television is perceived as more credible than radio by African Americans, whereas research with Hispanics ${ }^{18}$ found no major differences in the credibility assigned to both channels.

This article summarises the evaluations of various communication channels and sources of information regarding cigarette smoking among two communities of urban Hispanics in the United States and compares those responses with the perceptions given by a group of non-Hispanic whites from the same urban environments. Hispanics currently account for well over $10 \%$ of the total population of the United States and they are expected to become the largest ethnic group early in the next century. Data on cigarette smoking prevalence among Hispanics show worrisome patterns requiring the design of targeted prevention interventions. For example, Hispanic men $(28 \%)$ report smoking cigarettes in proportions that are comparable to those of nonHispanic white men $(28 \%)$ whereas Hispanic women $(16 \%)$ report cigarette smoking in proportions that are lower than those of nonHispanic white women $(24 \%) .{ }^{21}$ Hispanic high school seniors report cigarette smoking prevalences that are lower than those of nonHispanic whites but higher than those of African American and Asian American youth, ${ }^{22}$ whereas the 1993 Youth Risk Behavior Survey showed current cigarette use prevalence for Hispanics $(28.7 \%$ ) that was slightly lower than that of non-Hispanic whites $(33.7 \%)$ but higher than among African Americans $(15.4 \%) .{ }^{23}$ Recently, and in part as a response to these statistics, there has been an effort by various researchers and state agencies (such as California's Department of Health Services) to develop targeted interventions specifically designed for Hispanics. ${ }^{24-27}$ Future prevention and cessation campaigns targeting Hispanics will benefit from the data presented below, which will allow interveners to choose optimal sources of and channels for disseminating information.

In analysing the data reported here, the possible role of acculturation on the evaluations of the various sources and channels was studied. This was done because research has shown that, among Hispanics, acculturation seems to be related to cigarette smoking prevalence $^{28,29}$ as well as to a number of other variables that may be relevant to the design of preventive interventions including choice of media. ${ }^{17}$ In addition, a previous study by the author ${ }^{18}$ showed differences in the perceived qualities of various sources and channels of information when dealing with the prevention of HIV. It was expected that the less acculturated Hispanics would differ in thegir evaluations from the more acculturated anp that the responses of the latter would approah those of the non-Hispanic white respondent

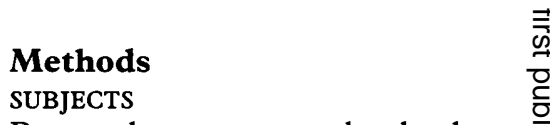

Respondents were randomly chosen $\frac{\overline{5}}{\text { from two }}$ southwestern cities in the United States: San Francisco, California and Housto Texas. These cities were chosen because each has a large number of Hispanic residents and because they are located in two states with different approaches to tobacco contel. A total of 544 Hispanics (266 in San Fra若isco and 278 in Houston) and 542 non-Hispanic whites (233 in San Francisco and 309 inciHouston) were interviewed over the telephong. Overall, $55.5 \%$ of the Hispanic respondents and $56.0 \%$ of the non-Hispanic whites were fenale. The mean age was 35.4 years for Hispani $\vec{\xi}_{5}$ and 38.9 years for non-Hispanic whites. A Parge proportion $(59.4 \%)$ of the Hispanics $\overrightarrow{a n d}$ of the non-Hispanic whites $(53.3 \%$ ) reposfed being married at the time of the interview while $30.7 \%$ of Hispanics and $33.7 \%$ of nonHispanic whites reported being fingle and never married. The Hispanic ropondents reported a lower average numbef of years spent in formal education (mean $=10.8$ years) compared with non-Hispanic white (mean = 15.2 years). There were differences also across ethnic groups in reported incowne, with Hispanics reporting an average famity income of \$20000-25000 and the non-Hisp reporting an average family ingcome of $\$ 35000-50000$. The majority $(68.8 \%)$ of the Hispanic respondents and of the nom-Hispanic whites $(76.2 \%)$ reported employm outside the home in the two weeks before survey.

Most of the Hispanic respondents $(73 \%)$ reported being born outside the Ungated States with the largest numbers being born In Mexico $(56.2 \%)$ and Central America $5(36.0 \%)$. Foreign-born Hispanic respondentshad lived in the United States for an average of 13.4 years with $19.2 \%$ reporting having Nlived less than five years in the United States. The majority of the Hispanic respondent?lanswered the interview in Spanish $(70.0 \%)$.

\section{SURVEY INSTRUMENT}

$\stackrel{\substack{0 \\ \mathbb{D}}}{\stackrel{2}{+}}$

Respondents were asked to rate a wumber of possible channels of information ongthe health effects of cigarette smoking such $\frac{\mathbb{S}}{9}$ radio or television commercials, newspaperळor magazine articles, pamphlets, books, posters, television news or radio news, billbøards, bus posters, and serialised "soap operas in in print ("fotonovelas") or on television (c) ("telenovelas"). Each channel was rated in erms of its credibility (for example, "Would you believe a message about the effects of smoking cigarettes if it was presented in television commercials?") and their behavioural motivational 
power (such as "Would you quit smoking if it was suggested in television commercials?"). Respondents also were asked to rate a variety of health information sources (an actor, singer, athlete, physician, priest or minister, politician, teacher, friend, child, peer of the respondent, newscaster, person with cancer, pregnant woman, and someone's parents). Each possible source of information was rated on its perceived credibility (for example, "Would you believe a message about the effects of smoking cigarettes if it was presented by an athlete?"); expertise (for example, "Would you consider an athlete an expert on the topic of the health effects of smoking cigarettes?"); trustworthiness (for example, "Could you trust an athlete when talking about the health effects of smoking cigarettes?"); and its perceived behaviour change motivational power (for example, "Would you quit smoking if it was suggested by an athlete?"). The interview schedule also included standard sociodemographic questions and the SASH, an acculturation scale specifically developed for Hispanics. ${ }^{32,33}$ This scale has four items measuring linguistic preferences and use and has been found to be highly valid and reliable with Hispanics. All items were submitted to double translation procedures and to decentering. ${ }^{34}$

\section{PROCEDURE}

Respondents were randomly chosen from the telephone directories of both cities (San Francisco, California and Houston, Texas). A household was judged to be eligible if those answering the telephone identified themselves as members of one of the two ethnic groups. Within a given household, the respondent was selected by asking for the resident who had most recently celebrated a birthday and who was between 18 and 60 years of age. Four follow-up calls were made whenever the respondent was not available. The surveys were conducted in the language of choice of the respondents (English or Spanish) by highly trained and experienced bilingual and bicultural interviewers. A technical problem makes it impossible to report accurate refusal rates for this study, although previous studies ${ }^{35}$ conducted by the author following similar pro-

Table 1 Evaluation of channels of information regarding cigarette smoking

\begin{tabular}{lccccc}
\hline & \multicolumn{2}{c}{ Credibility } & & \multicolumn{2}{c}{ Behavioural motivator } \\
\cline { 2 - 3 } \cline { 5 - 6 } & Hispanics & Whites & & Hispanics & Whites \\
\hline TV commercials & 79.4 & $65.9^{\star}$ & & 51.8 & $28.1^{\star}$ \\
Radio commercials & 70.4 & 61.3 & & 49.2 & $27.7^{\star}$ \\
Telenovelas & 50.6 & NA & & 40.6 & NA \\
TV news & 82.1 & 74.5 & & 58.8 & $36.0^{\star}$ \\
Pamphlets & 84.0 & 82.9 & & 62.1 & $44.8^{\star}$ \\
Books & 88.1 & 86.3 & & 69.3 & $49.4^{\star}$ \\
Posters & 74.0 & $62.5^{\star}$ & & 5.9 & $31.2^{\star}$ \\
Radio news & 74.6 & 70.2 & & 53.3 & $33.7^{\star}$ \\
Fotonovelas & 52.0 & $\mathrm{NA}$ & & 43.4 & NA \\
Newspaper articles & 86.4 & 82.5 & & 65.0 & $48.0^{\star}$ \\
Magazine articles & 83.6 & 82.5 & & 62.9 & $47.6^{\star}$ \\
Billboards & 70.5 & $53.2^{\star}$ & & 53.0 & $28.8^{\star}$ \\
Bus posters & 71.9 & $54.4^{\star}$ & & 52.6 & $28.6^{\star}$
\end{tabular}

All $\chi^{2}$ analyses were carried out between the two adjacent columns to the left of the asterisks. $\mathrm{df}=1,1025 ;{ }^{\star} \mathrm{p}<0.001$

$\mathrm{NA}=$ not applicable. cedures showed very low refusal rates for Hispanics (ranging from $3.1 \%$ to $4.7 \%$ ).

Telephone coverage for Hispanic and nonHispanic white households is fairly high in both cities sampled. In San Francisco, $1.98 \%$ 응 of non-Hispanic white households did not $\delta$ have a telephone according to the 1990 census compared with $3.73 \%$ for Hispanic house- 으․ holds. In Houston, the corresponding figures are $17.6 \%$ for Hispanic households and $3.41 \% \stackrel{\infty}{\frac{D}{0}}$ for non-Hispanic whites.

\section{ANALYSIS}

The respondents' evaluations of the various sources and channels of information are repor-. ted here in terms of the proportion of respondents agreeing with a given question. The $\omega_{\sigma}^{\omega}$ data are reported separately for the evaluation $?$ of the various channels and sources. $\chi^{2}$ analyses were conducted for each of the dependent $\vec{\omega}$ measures studied (sources and channels) across ethnic groups. Bonferini's correction was used to avoid type I errors. The results of the $\vec{z}$ various $\chi^{2}$ analyses are not reported here but are available from the author. Following $\frac{\rho}{3}$ previous studies with the SASH, respondents $\vec{\theta}$ who scored less than 2.99 were considered to $\mathscr{\&}$ be low in acculturation and the rest were considered to be high in acculturation. ${ }^{30,31}$ In analysing the data, responses of members of a given ethnic group were collapsed across cities. This was done because there were few, if any, $\frac{\mathbb{Q}}{8}$ statistically significant differences across cities for the responses of members of a given ethnic $\frac{0}{3}$ group.

\section{Results}

\section{CHANNELS OF INFORMATION}

Ethnic differences

Table 1 presents the evaluations made by the Hispanic and non-Hispanic white respondents of the 13 possible channels of information for a health-promoting message regarding cigarette smoking. In general, although a larger $\delta$ proportion of Hispanics than of non-Hispanic whites rated the various channels as credible, 을 there were few statistically significant differences. The largest difference across ethnic groups was Hispanics rating billboards and N posters as more credible than non-Hispanic whites (table 1). Likewise, Hispanics were more likely to assign behavioural motivating power to a larger number of channels than non-Hispanic whites. In terms of perceived credibility, the data presented in table 1 show $\mathbb{D}$ a marked preference for printed channels and for electronic media news shows among Hispanics and non-Hispanic whites alike. Books, pamphlets, newspaper articles, television news, and magazine articles were perceived as credible by the largest proportions of respondents of both ethnic groups. Respondents from both ethnic groups also agreed on the five most frequently endorsed channels of information as having behaviour change motivational power: books, newspaper articles, magazine articles, television news, and pamphlets. The channels perceived as credible by 
Table 2 Evaluation of channels of information on cigarette smoking by acculturation level of Hispanic respondents

\begin{tabular}{llllll}
\hline & \multicolumn{2}{c}{ Credibility } & & \multicolumn{2}{c}{ Behavioural motivator } \\
\cline { 2 - 3 } \cline { 5 - 6 } & \multicolumn{2}{c}{ Acculturation } & & \multicolumn{2}{c}{ Acculturation } \\
\cline { 2 - 3 } \cline { 5 - 6 } & Low & High & & Low & High \\
\hline TV commercials & 81.8 & 74.4 & & 59.2 & $36.5^{\star}$ \\
Radio commercials & 74.1 & 62.8 & & 56.0 & $35.3^{\star}$ \\
Telenovelas & 53.0 & 45.0 & & 46.1 & $28.3^{\star}$ \\
TV news & 84.4 & 77.3 & & 65.6 & $45.0^{\star}$ \\
Pamphlets & 85.0 & 82.0 & & 65.3 & 55.6 \\
Books & 89.0 & 86.0 & & 72.6 & 62.6 \\
Posters & 78.3 & 65.1 & & 59.9 & $44.4^{\star}$ \\
Radio news & 79.8 & $64.0^{\star}$ & & 60.3 & $38.8^{\star}$ \\
Fotonovelas & 55.2 & 44.7 & & 47.8 & 33.5 \\
Newspaper articles & 86.9 & 85.4 & 66.5 & 62.0 \\
Magazine articles & 82.6 & 85.5 & 64.4 & 59.6 \\
Billboards & 75.1 & $61.0^{\star}$ & & 59.5 & $39.8^{\star}$ \\
Bus posters & 76.2 & 63.2 & 59.8 & $38.0^{\star}$ \\
\hline
\end{tabular}

All $\chi^{2}$ analyses were carried out between the two adjacent columns to the left of the asterisks. $\mathrm{df}=1,512 ;{ }^{\star} \mathrm{p}<0.001$

the lowest proportion of Hispanics were "telenovelas" ( $50.6 \%$ ) followed by "fotonovelas" $(52.0 \%)$ whereas among non-Hispanic whites, the channel perceived as credible by the lowest proportion of respondents was billboards $(53.2 \%)$.

\section{Gender differences}

An analysis of the data by gender of the respondents showed very few statistically significant differences in the proportion of respondents rating each channel of information as credible or as having behaviour change power. The only statistically significant differences found among Hispanics were that a larger proportion of women $(84.1 \%$ ) than of men $(73.8 \%)$ rated a television commercial as credible. The same was true for a television newscast $(75.9 \%$ of men and $87.3 \%$ of women). Among the non-Hispanic white respondents, a lower proportion of men $(77.7 \%)$ than of women $(86.4 \%)$ rated as credible a magazine article. There were no statistically significant gender differences in terms of the perceived behaviour change motivational power of the various channels.

Differences due to acculturation level

Table 2 presents the proportion of Hispanic respondents rating each of the various channels of information in terms of the respondents' level of acculturation. In general, greater proportions of low-acculturated Hispanic respondents rated the various channels as credible and as having behaviour change pogver than among the more acculturated. Overall, there were few statistically significant differences in the proportion of low- and highly accitlurated respondents who perceived the various channels as credible although the acc霖turation level seems to be more relevant in pfoducing statistically significant differences infthe proportions of respondents indicating the channel had behaviour change modivational power.

The five information channels frated as credible by the largest proportion of respondents were similar across accutturation groups (books, newspaper articles, œ્elevision news, pamphlets, and magazine carticles). These same channels were also considered as having behaviour change motivational power by the less and the more acculturated Hispanic respondents.

SOURCES OF INFORMATION

금

As mentioned above, respondents द्युso were asked to rate 14 possible sources of in rmation that could be used to disseminate infermation about the effects of cigarette smoking Four of the sources rated were part of the entertainment world (a television or movi actor, a

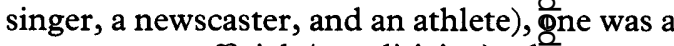
government official (a politician), thee were valued professional roles (a teacher, fppriest or minister, a doctor); one was a person with cancer, and the rest included acquainfances or peers of the respondent (a friend, someone's parents, a child, a peer, or a pregnantowoman). Table 3 shows the proportion of re@ondents who rated each of the sources in terfins of the ethnicity of the respondents.

\section{Ethnic differences}

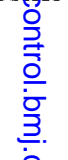

A larger proportion of Hispanic respondents evaluated positively each of the sêrces of information compared with the non Hispanic white respondents. A large numbertof those ethnic differences were statistically significant (table 3). Across both ethnic groupso a physician was perceived as credible, hăving ex-

Table 3 Evaluation of sources of information on health effects of cigarette smoking

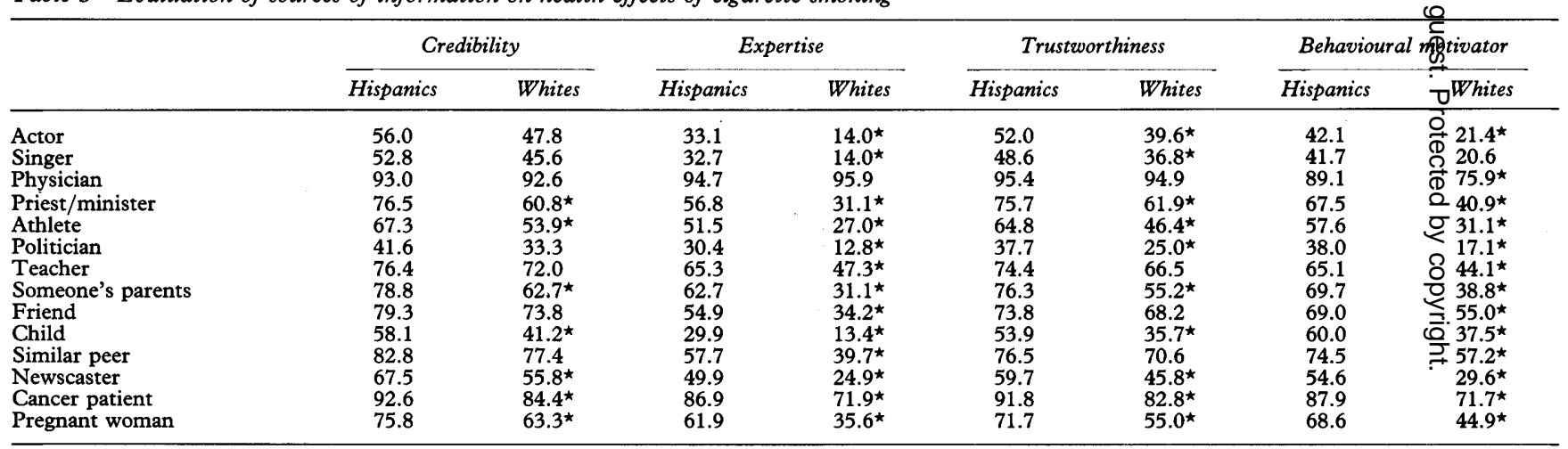

All $\chi^{2}$ analyses were carried out between the two adjacent columns to the left of the asterisks. $\mathrm{df}=1,1042 ;{ }^{\star} \mathrm{p}<0.001$. 
pertise, being trustworthy, and having behaviour change motivational power in greater proportions than any of the other sources of information about cigarette smoking. Respondents from both ethnic groups showed some differences in the five sources of information perceived as credible by the largest proportion of respondent. Hispanics favoured (in descending order) a physician, a person with cancer, a peer of the respondent, a friend, and a priest or minister, while non-Hispanic whites favoured (also in descending order) a physician, a person with cancer, a peer, a friend, and a teacher. Of special significance is the role of a priest or minister among Hispanic respondents. Priests or ministers are perceived to be credible, trustworthy, and to have behaviour change power by at least $70 \%$ of the Hispanic respondents. Also of interest is the relatively low proportion of respondents of both ethnic groups who rated politicians and entertainers as having any of the qualities evaluated. Although athletes and newscasters were rated higher than politicians and entertainers, their perceived power to motivate behaviour change is fairly limited in comparison with that of the five optimal sources mentioned above.

\section{Gender differences}

There were some statistically significant differences in the proportion of Hispanic men and women who considered some of the sources as credible. Hispanic men $(71.1 \%$ ) considered in lower proportions than women $(80.8 \%)$ that a priest or minister was a credible source of information on the health effects of cigarette smoking. The same was true for the perceived credibility of a pregnant women where men $(69.0 \%)$ considered her to be credible in lower proportions than women $(81.3 \%)$. Gender-based statistically significant differences were also found among Hispanics for the perceived trustworthiness of a priest $(69.9 \%$ of men and $80.6 \%$ of women) and of a pregnant woman $(65.3 \%$ of men $v s 77.1 \%$ of women). There were no statistically significant differences between Hispanic men and women in the proportions of respondents rating the various sources in terms of their expertise although there were some differences in the perceived power of the various information sources to make a person quit smoking. Hispanic men differed from Hispanic women ${ }_{0}^{-1}$ in the proportion of respondents rating the perceived behavioural power of a physiciano $(83.8 \%$ of men vs $93.3 \%$ of women), of a priest or minister $(61.0 \%$ of men $v s 72.8 \%$ of -

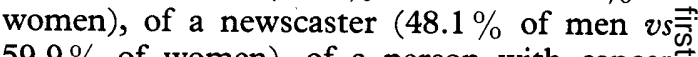
$59.9 \%$ of women), of a person with cancer $-\frac{7}{0}$ $(83.8 \%$ of men $v s 91.2 \%$ of women), and of a등 pregnant woman $(61.8 \%$ of men vs $74.1 \%$ of $\overline{\bar{c}}$ women).

Among non-Hispanic white respondents, gender-based statistically significant dif- ferences were less frequent. In terms of $\vec{\circ}$ perceived credibility, a lower proportion of $\vec{\omega}$ men $(66.1 \%)$ than of women $(76.5 \%)$ considered a teacher to be credible and the same $\vec{?}$ was true for someone's parents $(56.8 \%$ of men $\rightarrow$ vs $67.5 \%$ of women), for a friend of the respondent $(66.9 \%$ of men vs $79.1 \%$ of $\circ$ women), a child $(30.9 \%$ of men and $49.3 \%$ of women), a peer $(72.0 \%$ of men and $81.5 \%$ of $\vec{z}$ women), and a pregnant woman $\left(57.2 \%\right.$ of $\frac{\text { ले }}{\bar{O}}$ men and $68.3 \%$ of women). There were no $)$ statistically significant differences based on the $\vec{\oplus}$ gender of the non-Hispanic white respondents for the ratings of expertise or of trustworthiness except for a child being perceived as more trustworthy by women $(42.0 \%$ ) than by men $(28.0 \%)$ and the same was true for a person with cancer $\left(86.4 \%\right.$ of women $v s 77.7 \%$ of $\frac{\circ}{\Phi}$ men). A child was also perceived by lower proportions of non-Hispanic white men 응 $(30.7 \%)$ than of women $(43.0 \%)$ as having sufficient motivational power to make a person quit smoking.

\section{Differences due to acculturation level}

Table 4 presents the proportions of Hispanic respondents, in terms of their acculturation $\overrightarrow{\vec{\sigma}}$ level, who rated the various possible sources of $\frac{0}{\sigma}$ information in each of the four measures. In general, the less-acculturated Hispanic res- of pondents rated the various sources as having each of the four properties in greater propor- 은 tions than the more-acculturated respondents. $\frac{D}{2}$ Nevertheless, there were two sources con- 을 sidered to have each of the four characteristics o

Table 4 Evaluation of sources of information on cigarette smoking by acculturation level of Hispanic respondents

\begin{tabular}{|c|c|c|c|c|c|c|c|c|}
\hline & \multicolumn{2}{|c|}{ Credibility } & \multicolumn{2}{|c|}{ Expertise } & \multicolumn{2}{|c|}{ Trustworthiness } & \multicolumn{2}{|c|}{ Behavioural motivator } \\
\hline & \multicolumn{2}{|c|}{ Acculturation } & \multicolumn{2}{|c|}{ Acculturation } & \multicolumn{2}{|c|}{ Acculturation } & \multicolumn{2}{|c|}{ Acculturation } \\
\hline & Low & High & Low & High & Low & High & Low & High \\
\hline $\begin{array}{l}\text { Actor } \\
\text { Singer } \\
\text { Physician } \\
\text { Priest/minister } \\
\text { Athlete } \\
\text { Politician } \\
\text { Teacher } \\
\text { Someone's parents } \\
\text { Friend } \\
\text { Child } \\
\text { Similar peer } \\
\text { Newscaster } \\
\text { Cancer patient } \\
\text { Pregnant woman }\end{array}$ & $\begin{array}{l}61.8 \\
57.7 \\
93.9 \\
80.6 \\
72.9 \\
48.6 \\
77.2 \\
83.1 \\
81.1 \\
62.4 \\
85.8 \\
71.9 \\
93.6 \\
80.8\end{array}$ & $\begin{array}{l}44.9^{\star} \\
43.5 \\
91.3 \\
68.1 \\
56.0^{\star} \\
28.0^{\star} \\
74.7 \\
70.3^{\star} \\
75.8 \\
49.5 \\
76.9 \\
58.8 \\
90.7 \\
65.9^{\star}\end{array}$ & $\begin{array}{l}38.0 \\
36.8 \\
94.6 \\
62.5 \\
56.8 \\
35.9 \\
68.2 \\
71.0 \\
60.5 \\
32.1 \\
62.7 \\
54.4 \\
87.7 \\
68.1\end{array}$ & $\begin{array}{l}23.4^{\star} \\
24.6^{\star} \\
94.9^{\star} \\
45.7^{\star} \\
41.1^{\star} \\
19.4^{\star} \\
59.4^{\star} \\
45.7^{\star} \\
43.4^{\star} \\
25.1^{\star} \\
47.4^{\star} \\
40.6 \\
85.1 \\
49.1^{\star}\end{array}$ & $\begin{array}{l}57.5 \\
52.9 \\
96.0 \\
80.7 \\
69.8 \\
42.9 \\
76.1 \\
80.5 \\
75.9 \\
58.3 \\
79.0 \\
64.4 \\
93.1 \\
77.6\end{array}$ & $\begin{array}{l}40.8^{\star} \\
39.7 \\
94.3^{\star} \\
65.5^{\star} \\
54.6^{\star} \\
27.6^{\star} \\
70.7 \\
67.8 \\
69.5 \\
44.8 \\
71.3 \\
50.0 \\
89.1 \\
59.8^{\star}\end{array}$ & $\begin{array}{l}50.1 \\
49.0 \\
90.5 \\
74.8 \\
65.7 \\
46.2 \\
68.8 \\
75.0 \\
71.1 \\
64.9 \\
79.5 \\
61.8 \\
88.8 \\
75.3\end{array}$ & $\begin{array}{l}26.4^{\star} \\
27.5^{\star} \\
86.8^{\star} \\
53.0^{\star} \\
41.4^{\star} \\
22.1^{\star} \\
57.5^{\star} \\
59.1^{\star} \\
64.6^{\star} \\
50.3^{\star} \\
64.6^{\star} \\
40.9^{\star} \\
86.2^{\star} \\
55.2^{\star}\end{array}$ \\
\hline
\end{tabular}

All $\chi^{2}$ analyses were carried out between the two adjacent columns to the left of the asterisks. $\mathrm{df}=1,522 ;{ }^{\star} \mathrm{p}<0.001$. 
by the largest proportion of respondents within each acculturation level group (physician and person with cancer) and there were no statistically significant differences due to the respondents' level of acculturation. It is particularly interesting that a priest or minister was considered to have each of the various characteristics by a higher proportion of the less acculturated Hispanic respondents compared with the more acculturated. As was true for Hispanics and non-Hispanic whites in general, politicians and entertainers continue to be evaluated as having each of the four properties in fairly low proportions particularly among the less acculturated Hispanic respondents.

\section{Discussion}

The data reported here showed a number of statistically significant differences in the proportion of respondents assigning various perceived qualities to sources and channels of information regarding cigarette smoking. These differences were found to exist across ethnic groups (Hispanics and non-Hispanic whites), the respondents' gender (particularly among Hispanics), and the acculturation level of the Hispanic respondents. In many cases, Hispanics, and particularly the lessacculturated Hispanics, rated each of the channels and sources of information as having the various characteristics in greater proportions than non-Hispanic whites. Nevertheless, there was a cluster of channels (printed media and television news) and of sources (physicians, people with cancer, friends, and peers) that were positively evaluated by large proportions of the respondents in both ethnic groups.

The similarities in the proportions of respondents of both ethnic groups that rated certain channels and sources as having the various characteristics is an encouraging finding that supports a number of current massive public health efforts to curtail the use of cigarettes in the United States. The fact that Hispanics tended to rate positively the various characteristics of most channels and sources in greater proportions than non-Hispanic whites may imply that culturally appropriate ${ }^{6}$ health education interventions using optimal sources and channels may have a greater chance at success among Hispanics than among nonHispanic whites. This assumption is based on the significance of credibility, trustworthiness, expertise, and motivational power in producing behaviour changes. ${ }^{3,8-10}$

The high proportions of respondents of both ethnic groups who perceived physicians and people with cancer as having the various characteristics can be explained in terms of their perceived levels of expertise through direct contact with the effects of cigarette smoking. Attitude change research has shown that expertise is one of two key components in establishing the credibility of a source, the other being trustworthiness. " The high proportion of respondents rating a physician as an optimal source of information about the health effects of cigarette smoking is a finding that replicates previous results on the perceived credibility of sources of AIDS information ${ }^{18}$ among Hispanics where a physician, an AIDS counsellor, and a person with ADS were considered as the most credible sources of information, and with Johnson and Neishcke's study $^{15}$ of cancer-related information where women again rated physicians verì highly. These studies point to the need tevelop appropriate strategies for the training of physicians in the delivery of tobacco etucation ${ }^{36}$ that can provide a sense of self-icacy to physicians and deal with other \$roblems identified in the literature as deterrefts for the involvement of physicians in tobaces control whenever they interact with patients. ${ }^{37}$

The possible role of peers and Exiends in transmitting credible and trustworthy information on quitting cigarette smokinges another finding that is noteworthy here. The high ratings received by these two sürces of information could point to the need develop culturally appropriate intervention $s^{24,25}$ that train friends and peers of smokers $i$ culturespecific approaches to provide rotivating messages that move smokers to obtain more information about quitting and irę actually trying to quit.

The high proportion of Hispghic respondents who rated positively a psiest or a minister opens new possibilities for $\overline{\text { Dew }}$ sources of targeted health information. experiences with African American communities $^{38,39}$ have shown promising resubts where ministers serve as sources of heath information. The results of this study susgest that the same may be true among fispanics, particularly Hispanic women. The diterature on Hispanic religiosity has tended go show a strong respect for priests and minis gers and a search for church-based communify experiences. ${ }^{40}$ Priests and ministers serving Hispanic communities could be trained to shape healthrelated behavioural norms including quitting of cigarette smoking.

Although these data were collectôgd in two southwestern cities in the United Stafes among predominantly Mexican American Hispanics, the data possibly could be generalised to other urban Hispanics who share the san norms, attitudes, and expectancies related torcigarette smoking. The data are, of course, limited by the fact that they were obtained by seff-report. Future research should be designed to behaviourally validate these responseso Another possible limitation of the data is the fact that the universe of possible respondents was made up of households with telephones. WIIle those universes are quite large given the portion of households with no flephone, short-term residents with no telepRone may have been missed. Nevertheless it \$ould be kept in mind that according to the 1980 census, a large proportion of Hispanics ore urban residents $(90.4 \%$ ) compared witho.a much lower proportion (76.2\%) of non-fispanics. Future studies must also determine the possible differences between smokers and nonsmokers in their perceptions of the various sources and channels of tobacco information. 
Despite these limitations, the results reported above provide important guidelines for the design of targeted, culturally appropriate interventions that will control the tobacco epidemic among Hispanics in the United States. Choosing the optimal sources and channels of information as identified here, should produce more effective and efficient interventions. ${ }^{41-43}$

This study was funded by grant AA09432 from the National Institute on Alcohol Abuse and Alcoholism and from the Center for Substance Abuse Prevention (Gerardo Marin, Principal Investigator). The author wishes to express his appreciation to Richard Matens, Samuel Posner, and Rosa Marcano for their continuous help in all aspects of this study.

1 Hovland CI, Janis IL, Kelley HH. Communication and persuasion. New Haven, Connecticut: Yale University Press, 1953.

2 McGuire WJ. Attitudes and attitude change. In: Lindzey $\mathrm{G}$, Aronson E, eds. Handbook of social psychology. New York: Random House, 1985: 233-346.

3 Bettinghaus EP. Persuasive communication. New York: Holt, Rinehart \& Winston, 1980.

4 Johnson JD, Meischke H. Women's preferences for cancer information from specific communication channels. $A m$ Behav Sci 1991; 34: 742-55.

5 Freimuth VS. The diffusion of supportive information. In: Albrecht TL, Adelman MB, eds. Communicating social support, Newbury Park, California: Sage, 1987: 212-37.

6 Marín G. Defining culturally-appropriate interventions: Hispanics as a case study. $\mathscr{f}$ Commun Psychol 1993; 21 : 149-61.

7 Catalano RF, Hawkins JD, Krenz C, et al. Using research to guide culturally appropriate drug abuse prevention. to guide culturally appropriate drug abuse

8 Chaiken S. Heuristic versus systematic information processing and the use of source versus message cues in persuasion. F Personality Soc Psychol 1980; 39: 752-66.

9 Chaiken S. The heuristic model of persuasion. In: Zanna MP, Olson JM, Herman CP, eds. Social influence. Hillsdale, New Jersey: LEA, 1987: 3-40.

10 Johnson HH, Scileppi JA. Effects of ego involvement conditions on attitude change to high and low credibility communicators. F Personality Soc Psychol 1969; 13: 31-6.

11 Rubin AM. Uses, gratifications, and media effects research. In: Bryant J, Zillman D, eds. Perspectives on media effects, Hillsdale, New Jersey: Lawrence Erlbaum, 1986: 281-301.

12 Katz E, Gurevitch $M$, Haas $H$. On the use of the mass media for important things. Am Sociol Rev 1973; 38: 164-81.

13 Lichty IW. Video versus print. Wilson $Q$ 1982; 6: 48-57.

14 Patterson TE. The mass media: How Americans choose their president. New York: Praeger, 1980.

15 Johnson JD, Meishcke $H$. Differences in evaluations of communication channels for cancer-related information. f Behav Med 1992; 15: 429-45.

16 Faber RJ, O'Guinn TC, Meyer TP. Diversity in the ethnic media audience: A study of Spanish language broadcast preference in the U.S. Int $\mathcal{F}$ Intercult Relations 1986; 10 347-59.

17 Alcalay R, Sabogal F, Marín G, Pérez-Stable EJ, VanOss Marin B, Otero-Sabogal R. Patterns of mass media use among Hispanic smokers: Implications for community interventions. Int $Q$ Commun Health Educ 1987-1988; 8: interven $341-50$.

18 Marín G, VanOss Marín B. Perceived credibility of channels and sources of AIDS information among Hispanics. AIDS Education and Prevention 1990; 2: 154-61.

19 Harris MB, Harris RJ, Davis SM. Ethnic and gender differences in Southwestern students' sources of information about health. Health Educ Res 1991; 6: 31-42.

20 Cernada GP, Darity WA, Chen TTL, et al. Mass media usage among Black smokers: A first look. Int $Q$ Commun Health Educ 1989-1990; 10: 347-64.

21 US Centers for Disease Control and Prevention. Cigarette smoking among adults - United States, 1991. MMWR $1993 ; 42: 230-3$.
22 Bachman JG, Wallace JM, O’Malley PM, Johnston LD, Kurth CL, Neighbors HW. Racial/ethnic differences in smoking, drinking, and illicit drug use among American high school seniors, 1976-89. Am f Public Health 1991; 81: $372-7$.

23 US Centers for Disease Control and Prevention. Youth응 Risk Behavior Surveillance-United States, 1993. MMWR 1995; 44 : SS-1.

24 Marín G, VanOss Marín B, Pérez-Stable EJ, Sabogal F, 글 Otero-Sabogal R. Changes in information as a function of a culturally appropriate smoking cessation community intervention for Hispanics. Am $\mathcal{F}$ Commun Psychol 1990; 18: 847-64.

25 Pérez-Stable EJ, VanOss Marín B, Marín G. A comprehensive smoking cessation program for the San Francisco Bay Area Latino community: Programa Latino Para Dejar de Fumar. Am $\mathcal{F}$ Health Promotion 1993; $7: \overline{\bar{c}}$ $430-42,475$.

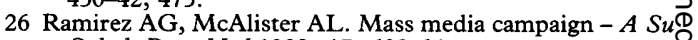
Salud. Prev Med 1988; 17: 608-21.

27 McAlister AL, Ramirez AG, Amezcua C, Pulley LV, Sterno MP, Mercado $M$. Smoking cessation in Texas-Mexicoborder communities: a quasi-experimental panel study. $\vec{O}$ Am $\mathcal{f}$ Health Promotion 1992; 6: 274-9.

28 Marin G, Pérez-Stable EJ, VanOss Marín B. Cigarette smoking among San Francisco Hispanics: The role of acculturation and gender. Am F Public Health 1989; $70: \stackrel{\overbrace{}}{\text { त }}$

29 Haynes SG, Harvey C, Montes H, Nickens H, Cohen BH. i Patterns of cigarette smoking among Hispanics in theUnited States: Results from HHANES 1982-84. Am $\mathfrak{F W}^{\mathrm{O}}$ Public Health 1990; 80: (supplement) 47-54.

30 Marín G, Sabogal F, VanOss Marín B, Otero-Sabogal R, 음 Pérez-Stable EJ. Development of a short acculturation scale for Hispanics. Hisp F Behav Sci 1987; 9: 183-205.

31 Marin G. Issues in the measurement of acculturation among Hispanics. In: Geisinger KF. ed. Psychological testing of Hispanics, Washington DC: American Psycho- $\frac{\rho}{工}$ logical Association, 1992: 235-51

32 Brislin RW, Lonner WJ, Thorndike RM. Cross-cultural $\overrightarrow{0}$ research methods. New York: Wiley, 1973.

33 Marin G, VanOss Marin B. Research with Hispanic. populations. Newbury Park, California: Sage, 1991.

34 Werner O, Campbell DT. Translating, working through interpreters and the problem of decentering. In: Naroll $\mathrm{R}$, Cohen R, eds. $A$ handbook of method in cultural anthropology, New York: American Museum of Natural History, 1970

35 Marín G, VanOss B, Pérez-Stable EJ. Feasibility of a telephone survey to study a minority community: Hispanics in San Francisco. Am $\mathcal{F}$ Public Health $1990 ; 80: \overrightarrow{\bar{O}}$ 323-6.

36 US Department of Health and Human Services. Tobacco and the clinician: interventions for medical and dental practice. Bethesda, Maryland: US Public Health Service, National Institutes of Health, National Cancer Institute, 1994. (NIH Publication No. 94-3693)

37 Kottke TE, Willms DG, Solberg LI, Brekke ML. Physician-delivered smoking cessation advice: issues identified during ethnographic interviews. Tobacco Control 1994; 3: 46-9.

38 Stillman FA, Bone LR, Rand C, et al. Heart, body, and soul: a church-based smoking-cessation program for urban African Americans. Prev Med 1993; 22 : 335-49. 으

39 US Department of Health and Human Services. Churches as an avenue to high blood pressure control. Washington Health, National Heart, Lung, and Blood Institute, 1992. (NIH Publication No. 92-2725.)

40 Marín G, Gamba RJ. The role of expectations in religious conversions: The case of Hispanic Catholics. Rev $R e$-음 ligious Res 1993; 34: 357-71.

41 DeBono KG, Harnish RJ. Source expertise, source at $\frac{D}{8}$ tractiveness, and the processing of persuasive information: a functional approach. F Personality Soc Psychol $1988 ; 55: 541-6$

42 Heesacker $M$, Petty RE. Field dependence and attitude change: source credibility can alter persuasion by affec- $N$ ting message-relevant thinking. $\mathcal{f}$ Personality $1983 ; 51: N$ $653-66$.

43 Wood W, Eagly AH. Stages in the analysis of persuasive messages: the role of causal attributions and message comprehension. F Personality Soc Psychol 1981; 40: 246-59. 